V. Pliugin, O. Petrenko, V. Grinina, O. Grinin, A. Yehorov

\title{
IMITATION MODEL OF A HIGH-SPEED INDUCTION MOTOR WITH FREQUENCY CONTROL
}

Purpose. To develop the imitation model of the frequency converter controlled high-speed induction motor with a squirrel-cage
rotor in order to determine reasons causes electric motor vibrations and noises in starting modes. Methodology. We have applied
the mathematical simulation of electromagnetic field in transient mode and imported obtained field model as an independent
object in frequency converter circuit. We have correlated the simulated result with the experimental data obtained by means of the
PID regulator factors. Results. We have made the simulation model of the high-speed induction motor with a squirrel-cage rotor
speed control in AnsysRMxprt, Ansys Maxwell and Ansys Simplorer, approximated to their physical prototype. We have made
models modifications allows to provide high-performance computing (HPC) in dedicated server and computer cluster to reduce
the simulation time. We have obtained motor characteristics in starting and rated modes. This allows to make recommendations
on determination of high-speed electric motor optimal deign, having minimum indexes of vibrations and noises. Originality. For
the first time, we have carried out the integrated research of induction motor using simultaneously simulation models both in
Ansys Maxwell (2D field model) and in Ansys Simplorer (transient circuit model) with the control low realization for the motor
soft start. For the first time the correlation between stator and rotor slots, allows to obtain minimal vibrations and noises, was
defined. Practical value. We have tested manufactured high-speed motor based on the performed calculation. The experimental
studies have confirmed the adequacy of the model, which allows designing such motors for new high-speed construction, and
upgrade the existing ones. References 15 , tables 3 , figures 15. Key words: induction motor, squirrel cage, high-speed, scalar control, ANSYS, RMxprt, Simplorer, high-performance computing, simulation, vibration, noise.

Разработана имитационная модель высокоскоростного асинхронного двигателя с короткозамкнутым ротором при скалярном частотном управлении в программном пакете AnsysMaxwell\&Simplorer. При моделировании на кластере высокопроизводительных расчетов выполнены параллельные вычисления полевой модели электродвигателя (AnsysMaxwell 2D) и модели, построенной на основе теории цепей (Ansys Simplorer), что позволило создать имитационные модели, приближенные к их физическим прототипам. Выполнен анализ пусковых характеристик, оптимизированы параметры электродвигателя. Даны рекомендации по выбору числа пазов статора и ротора высокоскоростного асинхронного двигателя, что позволило существенно уменьшить вибрации и шумы в режиме пуска. Библ. 15 табл. 3, рис. 15.

Ключевые слова: асинхронный двигатель, короткозамкнутый ротор, высокоскоростной, скалярное управление, ANSYS, RMxprt, Simplorer, высокопроизводительные вычисления, моделирование, вибрация, шум.

Introduction. High-Speed Induction Motors (HSIM) are induction motors working on high rotation speeds. At an instance HSIM, controlled from frequency converters (FC) with frequency $400 \mathrm{~Hz}$, have rotation speeds up to $30000 \mathrm{rev} / \mathrm{min}$.

In modern HSIM the increase of high speed is achieved without application of reducing gears and strap transmissions due to control from the FC. HSIM are well adjusted for a work in the weak field mode, providing the maximum wide speed range, restricted only by their mechanical construction.

At high rotation speed, there are considerable vibrations and noises both at starting and during a work in the rated mode. The high level of vibrations results in destruction of bearing in a short time, and the level of noises rising to a critical level. That is why a task of vibrations and noises diminishing in HSIM is actual for modern industrial enterprises and producers of electric engineering industry. To solve this task Ansys Maxwell \& Simplorer software both for induction motor design and transient simulation were used [1,2].

There are limited amount of works devoted to speed control of induction motor in Ansys Maxwell \& Simplorer software [3, 4]. In addition, existent works are not spared attention to forming of motor smooth starting mode and features for frequency control laws realization $[5,6]$.

In many of publications we can find only information of motor control theory or with coupling of Ansys software with Matlab/Simulink but without detail description of control system realization [3, 7, 8]. In known software products that allow the implementation of frequency control, the mathematical models are based on differential equations $[9,10]$.

A distinctive feature of the Ansys software is the ability to connect the simulation model of the control system (Ansys Simplorer) to the object of the electric machine, storing the full field data (AnsysMaxwell 2D \& 3D), including the state of the electromagnetic field values (magnetic induction vector with vector magnetic potential for 2D calculations and vector magnetic induction with a vector of magnetic field strength for problems in $3 \mathrm{D}$ formulation) in a given range of rotation frequencies. Thus, the jointly solved field problem and the mathematical model of frequency control increase the accuracy of calculations due to the operation of electromagnetic field components in space and time. The amount of data operated by the Ansys program, reaches 20-30 GB, which requires huge computing resources. Setting up a cluster of high-performance calculations (HPC), implemented by the authors using parallel computing technology, solved the problem of increasing the processing speed of a large data set.

Works devoted to the implementation of the described task are not elucidated in the technical literature or partially disclosed.

In this paper the material on the induction motor with a squirrel-cage rotor field model scalar control in

(C) V. Pliugin, O. Petrenko, V. Grinina, O. Grinin, A. Yehorov 
Ansys Maxwell and Ansys Simplorer with a detailed study of the simulation model is given for the first time.

Imitation modeling of the HSIM transient processes, considered in this work, allows to estimate their characteristics without making a full-scale sample, which significantly reduces the price of electric machines development and choosing their optimal parameters.

The aim of the paper is development and investigation of induction motor simulation model, controlled from the frequency converter with the using of parallel modeling on HPC cluster.

Simulation of an asynchronous drive in Ansys Maxwell. Now for the electric machines design and simulation the most used programs are Matlab/Simulink, SciLab, wxMaxima, Mathcad, Comsol Multiphysics. The advantage of Ansys Maxwell and Simulink package, compared to the known programs is an imitation of transients on mathematical models, near to their physical prototypes. Mainly it is realized due to objective approach in implementation of electric machines. The Ansys package includes three software products specialized in design and simulation of electric machines and electric drive systems: RMxprt, Maxwell 2D/3D and Simplorer [1]. It is possible to simulate electric drive with the motor, calculated previously in RMxprt (engineering project) or Maxwell 2D/3D (electromagnetic field project) [4]. The motor of RMxprt or Maxwell 2D/3D project is inserted as an object to the Simplorer shield and calculated simultaneously. The program RMxprt allows to make engineering calculation of electric machines based on the circuit of theory. On Fig. 1 the RMxprt model of an induction motor is shown.

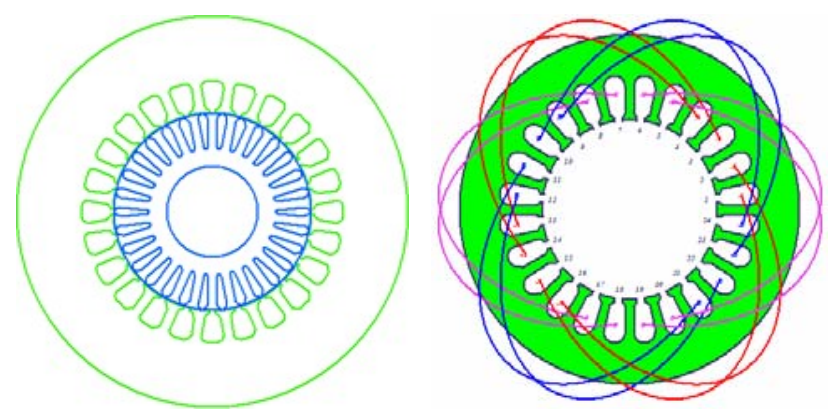

Fig. 1. Induction Motor with Squirrel Cage Rotor Model in Ansys RMxprt

Model, calculated in RMxprt, can be exported in Maxwell 2D/3D project for the solving the field task. The exported model is formed the task of transient simulation fully adjusted for solving, including setting of materials properties, border and symmetry conditions, winding excitation and electric circuit diagram, selection of moving object with inertia torque and motion function. Templates of charts and output data shield are created too. A model of induction motor example, automatically generated in Maxwell 2D on Fig. 2 is shown.

As a result of laboratory tests of induction motors E\&A of Swiss production (four-pole, $1010 \mathrm{~Hz}$ ) and Ukrainian - series DAV (two-pole, $505 \mathrm{~Hz}$ ), the presence of vibrations during the start-up and operation of the DAV motor was detected.

We have made numerous calculations of electromagnetic field of these motors in transient mode in
Ansys Maxwell 2D in order to find reasons that cause vibrations. Ansys offer a direct integration with a number of HPC software programs and provide parallel processing for running advanced application programs efficiently, reliably and quickly. We can enable queuing, set the design type, specify the distributed memory vendor and enable GPU for transient solves.

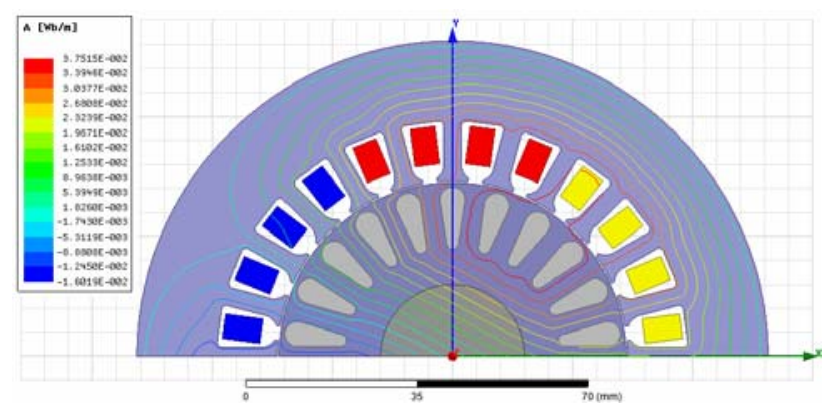

Fig. 2. Induction Motor with Squirrel Cage Rotor Model in Ansys Maxwell 2D

All results in Ansys Maxwell\&Simplorer shown in this paper, were got in HPC cluster with ten 2-core (with hyper-threading technology) processors Intel Core i3 $2.40 \mathrm{GHz} ; 48 \mathrm{~Gb}$ of server RAM; 64x OS Microsoft Windows HPC Server 2008 R2 SP2 and dedicated server (4 cores, $8 \mathrm{~Gb}$ RAM). Using of this cluster allow us to provide a way to solve complex problems in a short amount of time. Some of simulation results of motors with different ratio $Z_{s} / Z_{r}$, and rotor slots shapes in Table 1 are shown.

As calculations have shown, the presence of vibrations is caused by reversing brake torques that arise with a certain combination of stator $Z_{s}$ and rotor $Z_{r}$ slots.

All motors, that have braking torque at start mode and have high level of vibrations and noises, represented by Torque-Time chart, shown on Fig. 3. On this picture the mechanical torque, registered in experiment and equal to $4.5 \mathrm{Nm}$, is shown with a dotted line. The simulation torque, equal to $5.2 \mathrm{Nm}$, is represented by a solid curve.

All motors with positive torque at start mode and without vibrations, represented by Torque-Time chart, shown on Fig.4. On this picture the mechanical torque, registered in experiment and equal to $1.2 \mathrm{Nm}$, is shown with a dotted line. The simulation torque, equal to $1.35 \mathrm{Nm}$, is represented by a solid curve.

As we can see from Table 1, the shape and material of rotor slots does not have any influence on the braking torques presence and the level of vibrations and noises.

Analysis of got results have shown that in order to eliminate magnetic vibrations, the following correlations must be performed

$$
\begin{aligned}
& Z_{2}=2 p m g \pm 2 p, \\
& Z_{2}=Z_{1}+2 p,
\end{aligned}
$$

where $g-$ integer, « $\langle+\rangle$ is for motor mode and «-» is for generator mode.

It is need to know, that equations (1) are true only for high-speed motors with net frequency more than $200 \mathrm{~Hz}$. For motors with net frequency 50-60 Hz following the equations (1) will cause synchronous braking torques from high harmonics. 
Table 1 of frequency converter. High-speed motors can be started

Braking torques in high-speed motors with different ration of stator and rotor slots

\begin{tabular}{|c|c|c|c|}
\hline No. & $\begin{array}{c}Z_{s} / Z_{r} \\
\text { poles }\end{array}$ & $\begin{array}{l}\text { Rotor slot shape } \\
\text { and material }\end{array}$ & $\begin{array}{c}\text { Presence } \\
\text { of braking torque }\end{array}$ \\
\hline 1 & $\begin{array}{l}24 / 22 \\
2 p=2\end{array}$ & & Yes \\
\hline 2 & $\begin{array}{c}24 / 28 \\
2 p=4\end{array}$ & & No \\
\hline 3 & $\begin{array}{l}24 / 26 \\
2 p=2\end{array}$ & & No \\
\hline 4 & $\begin{array}{l}24 / 26 \\
2 p=2\end{array}$ & & No \\
\hline 5 & $\begin{array}{l}24 / 22 \\
2 p=2\end{array}$ & $\mathrm{Al}$ & Yes \\
\hline 6 & $\begin{array}{c}24 / 28 \\
2 p=4\end{array}$ & & No \\
\hline 7 & $\begin{array}{c}24 / 22 \\
2 p=4\end{array}$ & & Yes \\
\hline 8 & $\begin{array}{c}24 / 22 \\
2 p=2\end{array}$ & & Yes \\
\hline 9 & $\begin{array}{l}24 / 26 \\
2 p=2\end{array}$ & & No \\
\hline 10 & $\begin{array}{l}24 / 22 \\
2 p=2\end{array}$ & & Yes \\
\hline 11 & $\begin{array}{l}24 / 26 \\
2 p=2\end{array}$ & & No \\
\hline 12 & $\begin{array}{c}24 / 22 \\
2 p=2\end{array}$ & & Yes \\
\hline
\end{tabular}

High-speed induction motor simulation model. Both in RMxprt project and in Maxwell 2D/3D project, solved model can be exported as an object and becomes accessible by reference in Simplorer working shield. In Simplorer a complete electric supply and control system, including electric motors, different scopes and signals distribution are fully supported.

The design of transients in HSIM is impossible without the imitation of control system, built on the base during 5-10 $\mathrm{min}$ for the approaching of rated speed. For realization the law $U / f=$ const frequency and voltage signals will be linearly rising from 0 to the rated values in starting time $\left(t_{s t}\right)$ and in relative units $\left(f^{*}, u^{*}\right)$ will be coincide [11]:

$$
f^{*}=u^{*}=\left\{\begin{array}{rl}
k_{s t} t, & \text { if } 0<t \leq t_{s t} \\
1, & \text { if } t>t_{s t}
\end{array},\right.
$$

where $k_{s t}$ - the rate of tempo increase, $k_{s t}=1 / t_{s t}$.

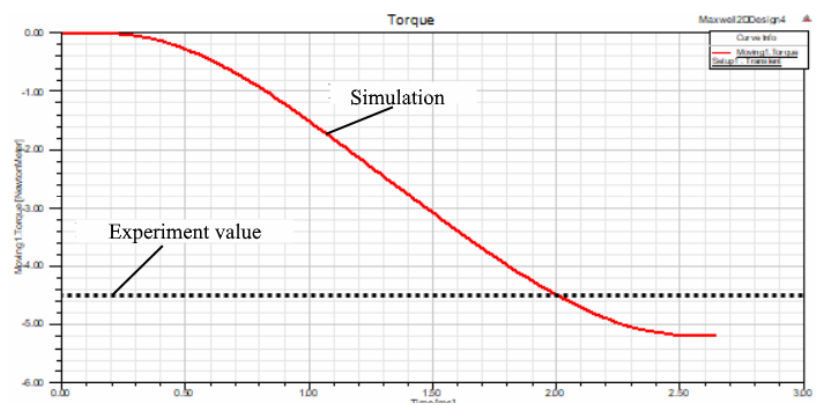

Fig. 3. Transient report of Maxwell 2D simulation for motor with vibrations

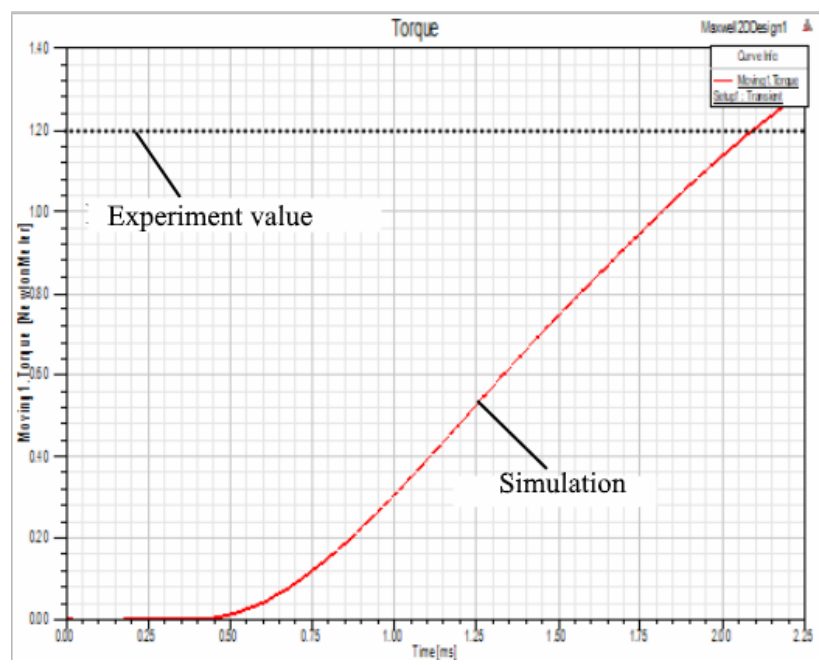

Fig. 4. Transient report of Maxwell 2D simulation for motor without vibrations

For the acceleration of motor starting processes, magnetizing first of all, voltage initial value $u^{*}$ must be greater than zero. In this case a voltage change law will be the next [11]:

$$
u^{*}=\left\{\begin{array}{cl}
u_{0}^{*}+\left(1-u_{0}^{*}\right) k_{s t} t, & \text { if } 0<t \leq t_{s t}, \\
1, & \text { if } t>t_{s t}
\end{array}\right.
$$

where $u_{0}^{*}$ - voltage relative value, $u_{0}^{*}=u^{*}(0)$.

On Fig. 5 voltage and frequency signals realization in Simplorer design sheet are shown.

Below is decryption of blocks on Fig. 5:

- both STEP6 and INTEGRAL blocks forms time function (STEP6 block has Time Step value 0, Final Value 1 and Initial Value 1);

- GAIN6 block scales time value to starting time $1 / t_{p}$;

- LIMIT1 block limits a signal at the level \pm 1 ;

- CONST5 block sets the boost voltage value (in relative units);

- GAIN block with the label $U$ calculates $1-u_{0}$ value by equation (3); 
- GAIN block with the label $U f$ has value 1 and finalizes the equation (3);

- GAIN block with the label $f$ has a rated frequency value and calculates actual frequency value in $\mathrm{Hz}$;

- GAIN block with the label speed converts speed frequency value from $\mathrm{Hz}$ to $\mathrm{rad} / \mathrm{s}$ and has value $60 / p$;

- Data block ICA sets the model constant parameters values.
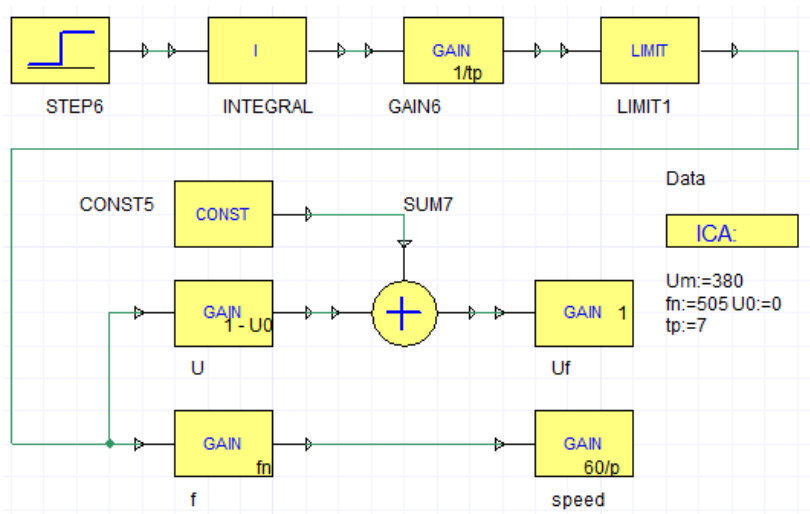

Fig. 5. $U / f$ control signals realization in Simplorer

AC voltage source in Simplorer forming the output electric voltage with given function. If we set the frequency signal on $\mathrm{AC}$ voltage input port, we will get an error result. Instead of the expected voltage equation $U=U_{m} \cdot \sin \left(\omega t+\varphi_{0}\right)$ we will obtain $U=U_{m} \cdot \sin \left(\omega(t) t+\varphi_{0}\right)$ where we have a variable angular speed function $\omega(t)$ under the sinus instead of constant value $\omega$. If frequency is linearly growing, the motor speed will be double from the rated value. To obtain the correct frequency signal, it is necessary to change the form of AC voltage Sourceblock in property Simplorer from harmonic time controlled function to EMF value. Also it is need to take an integral from variable speed function to get the correct angle value $\delta=\int \omega(t) d t$ as on Fig. 6 is shown.

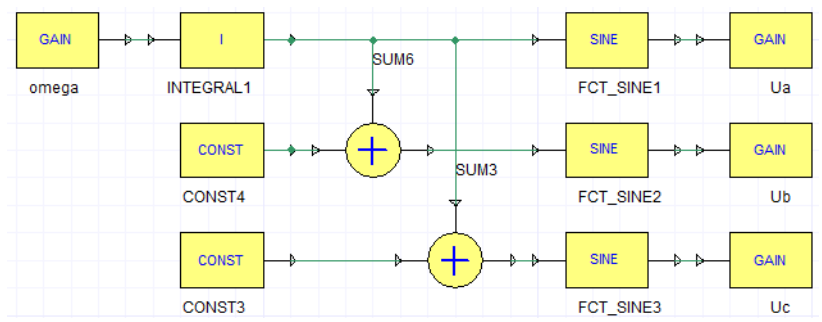

Fig. 6. AC Voltage Source signals block diagram in Simplorer

Below is decryption ofblocks on Fig. 6:

- GAIN block with the label omega has the value $2 \pi$ and calculates angular speed;

- CONST4 block has the value $-2 \pi / 3$ and give time shift value for phase $\mathrm{B}$;

- CONST3 block has the value $2 \pi / 3$ and give time shift value for phase $\mathrm{C}$;

- GAIN blocks with the labels $U a, U b$ and $U c$ with the same value $U_{f}$ converts voltage value from relative to real (V) units;

- SINE block is standard sinus function.

The full block diagram of induction motor scalar control in Simplorer on Fig. 7 is shown. The induction motor model in presented block diagram is an imported object from RMxprt project.

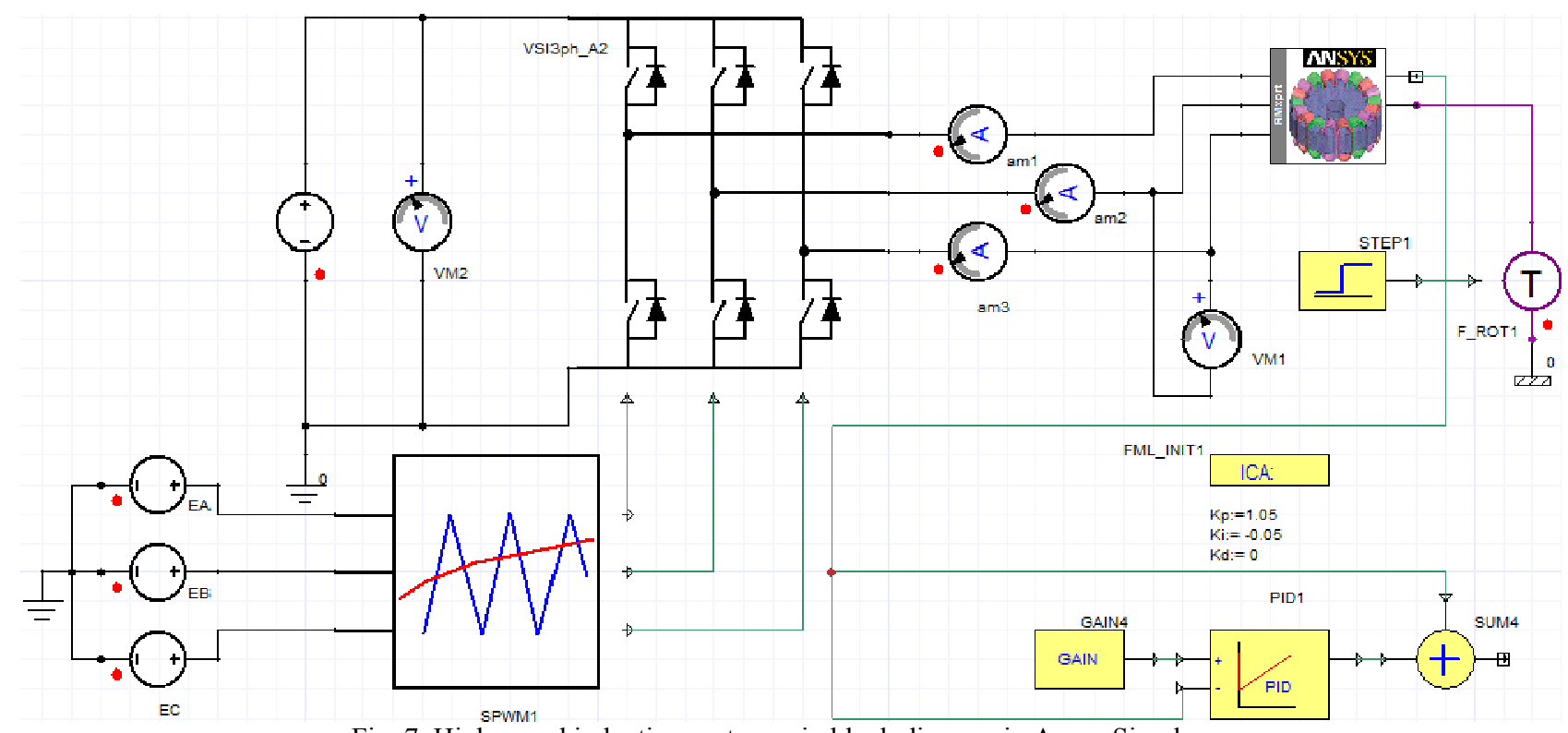

Fig. 7. High-speed induction motor main block diagram in Ansys Simplorer

Description of structure scheme shown on Fig. 7:

- $E A, E B$ and $E C$ blocks is AC Voltage source blocks and takes values from $U a, U b$ and $U c$ GAIN blocks respectively;

- SPWM1 is sinusoidal PWM block;

- DC Voltage source block has the value $U_{m} \sqrt{2}$;

- VSI3phA2 block is Voltage Source Inverter;
- GAIN4 block converts the motor speed from $\mathrm{rev} / \mathrm{min}$ to $\mathrm{rad} / \mathrm{s}$ and has a value $2 \pi / p$;

- PID controller block takes parameter values from ICA block;

- summation block SUM4 sends the output speed value to the GAIN block with the label omega (Fig. 8);

- F_ROT1 and STEP1 blocks realizes the mechanical torque value on motor shaft. 
Simulation results. Before the transient simulation an induction motor in authors' design Java program [12, 13], Ansys RMxprt [14] and Ansys 2D [15] was developed. As induction motor a high-speed motor «DAV-22» of Ukraine production was taken.

The housing-less bipolar induction motor with a rated power $20 \mathrm{~kW}$, line voltage $380 \mathrm{~V}$ and frequency $505 \mathrm{~Hz}$ has a built-in version and serves for driving a high-speed turbine.

The test bench was located in a vibro-acoustic chamber. At the stand, the electric motor was tested in idle mode, locked rotor motor and was connected to the Altivar (Schneider Electric production) frequency converter. The start of the electric motor was carried out according to the soft start program set in the frequency converter with a discrete frequency adjustment from $10 \mathrm{~Hz}$ to $505 \mathrm{~Hz}$. Boost voltage was set to $50 \mathrm{~V}$ value.

During the tests, the currents in the motor phases, the three phases voltage of the motor and the frequency converter, frequency converter output frequency, the rotation speed, the noise and vibration levels, the temperature of the stator windings, as well as the moving torque value were registered. Summary data of the experiment and modeling results in Table 2 is given.

Table 2

High-speed induction motor data

\begin{tabular}{|l|c|c|c|}
\hline \multirow{2}{*}{\multicolumn{1}{|c|}{ Parameter Name }} & \multicolumn{3}{|c|}{ Parameter Value } \\
\cline { 2 - 4 } & Model & Experiment & Deviation, \% \\
\hline Rated current, A & 36.45 & 39.05 & 6.66 \\
\hline Efficiency, \% & 91.25 & 90.10 & 1.28 \\
\hline Moving speed, rev/min & 30064 & 29994 & 0.23 \\
\hline Starting current ratio & 6.84 & 6.2 & 10.33 \\
\hline Starting torque ratio & 0.69 & 0.61 & 13.11 \\
\hline Braking torque ratio & 3.01 & 2.6 & 15.77 \\
\hline Copper losses, W & 378 & 361 & 4.71 \\
\hline Rotor losses, W & 221 & 190 & 16.32 \\
\hline Steel looses & 404 & 400.1 & 0.97 \\
\hline Rated torque, Nm & 6.35 & 6.37 & 0.31 \\
\hline
\end{tabular}

Comparative diagrams of the calculated parameters and parameters obtained as a result of experimental studies on Fig. 8-10 are shown. The symbol «M» on the diagram columns denotes the columns relating to the modeling, and the symbol «E» - to the experiment.

Analyzing the obtained results, the estimation error can be divided on three categories: energy, mechanical and power losses. In the energy category, which includes currents in the stator windings, efficiency and the starting current ratio, the highest convergence has the efficiency (deviation $1.28 \%$ ) and the smallest one - the starting current ratio (10.33\%).In the mechanical category (moving torques and speed), the minimum deviation of the calculated data from the experimental ones is the rated speed $(0.23 \%)$ and the rated torque $(0.31 \%)$, and the maximum - the braking torque $(15.77 \%)$.

In the losses category the most accurately calculated is steel loss (deviation $0.97 \%$ ), and the greatest error in the determination are losses in the rotor $(16.32 \%)$. The average error based on the results of calculation and experiment is $6.97 \%$.

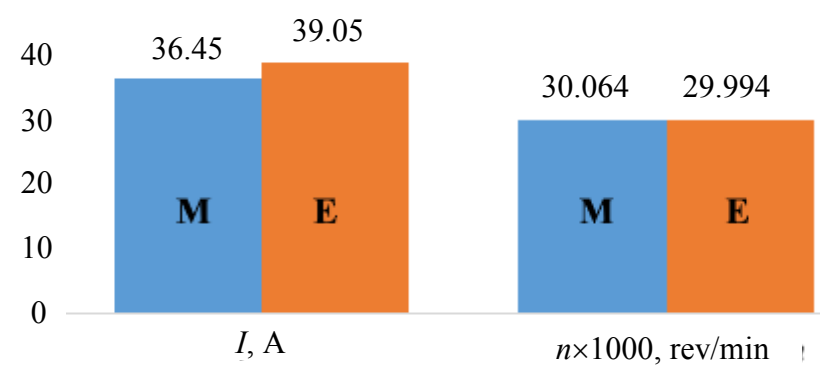

Fig. 8. Diagram of calculation and experiment results: rated current $(I)$ and moving speed $(n)$

$8 \quad 6.84$

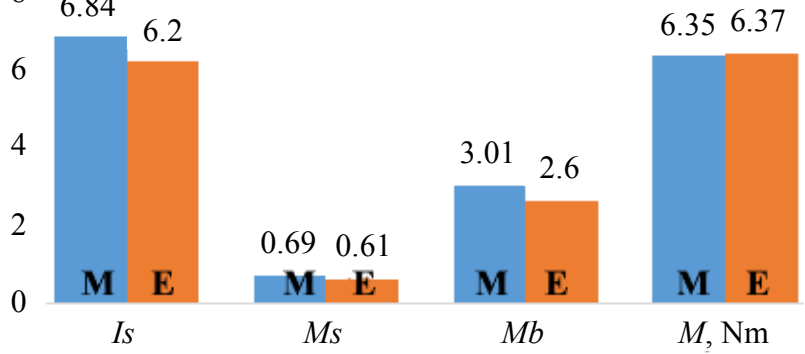

Fig. 9. Diagram of calculation and experiment results: starting current $(I s)$ and torque $(M s)$ ratio, braking $(M b)$ and rated $(M)$ torques

1

0.910 .9

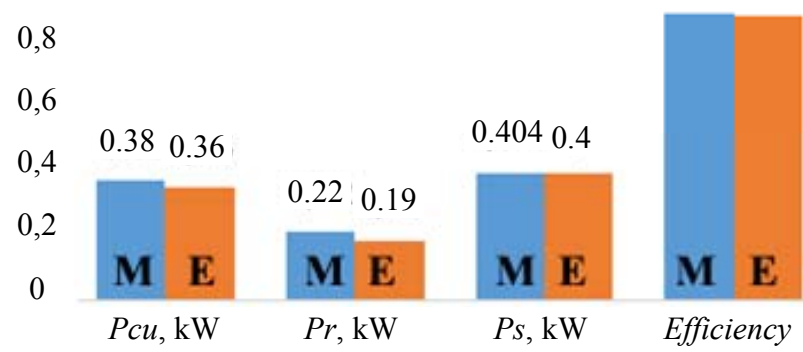

Fig. 10. Diagram of calculation and experiment results: copper $(P c u)$, rotor $(P r)$ and steel $(P s)$ losses and efficiency

The high discrepancies between the calculated values of the results obtained as a result of the full-scale experiment are due to the simplifications of the mathematical model (the field in the zone of the frontal parts was not calculated, the cross-section of the machine in the field calculation was considered without taking into account the slot skew, the properties of the steel were determined by main magnetization curve without splitting it into the tooth and yoke zones, did not take into account the presence of bearing shields).

Meanwhile, integral parameters, such as efficiency, current, rated torque, important for the evaluation of the model, have high convergence, which indicates the acceptability of the obtained results for engineering calculations.

In addition, the $100 \%$ convergence of mathematical modeling is the fact of confirmation or absence of increased vibrations with different combinations of the number of stator and rotor slots.

After Ansys Maxwell \& RMxprt calculation, the motor object with the full base of field calculations was imported in Ansys Simplorer. In simulation, as well as in real experiment, the soft start time value was $4 \mathrm{~s}$ and total 
simulation time was $6 \mathrm{~s}$. The speed vs time graph on Fig. 11 is shown. Dash lines represented the given speed and the solid one - actual motor speed in rev/min.

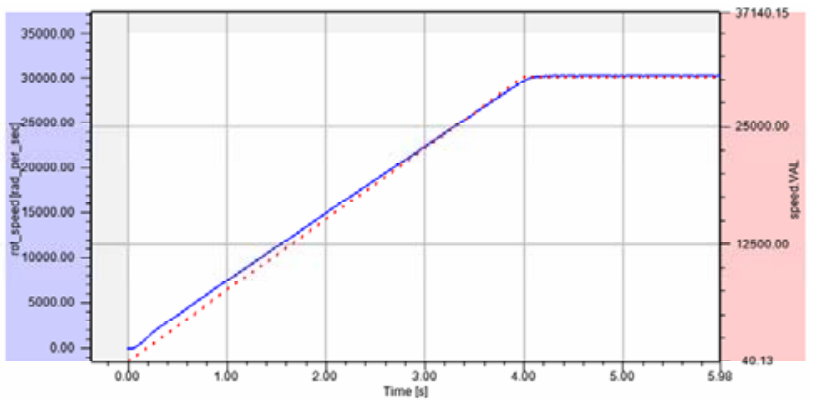

Fig. 11. Motor moving speed, rev/min vs time

Motor currents on Fig. 12 are shown. The dashed line (bottom graph, scaling by the time axis for steady state) indicates the value of the motor current obtained during the experimental studies.
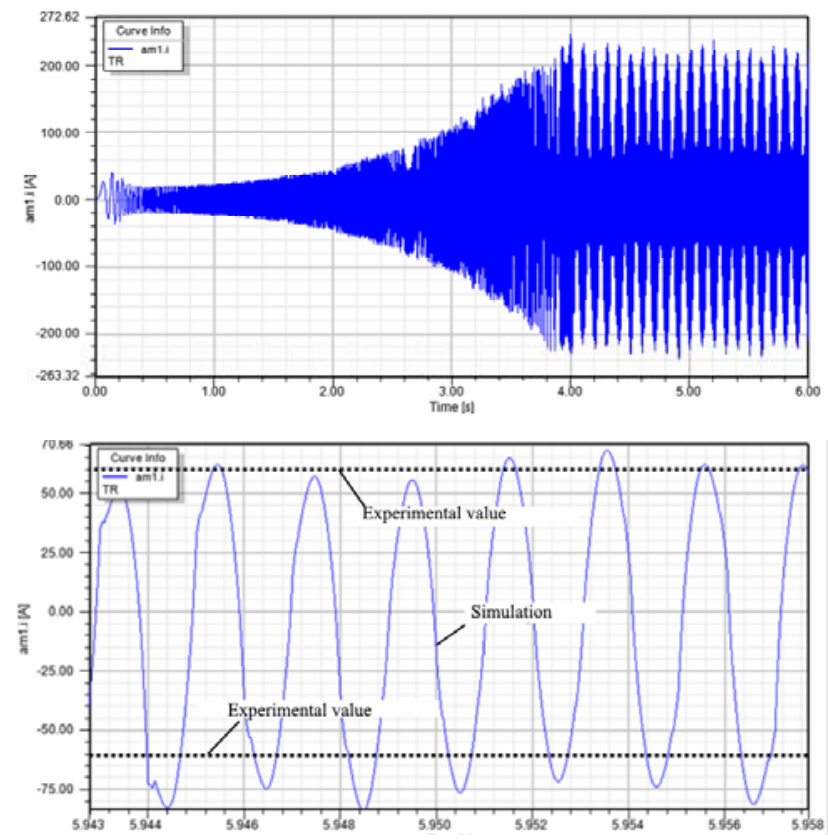

Fig. 12. Motor phase currents vs time

The graph of the one phase line voltage on Fig. 13 is shown.

The characteristic of the motor torque for a mode with vibrations on Fig. 14 is shown (scaled section on the time axis). The dashed line indicates the torque magnitude registered in experiment. This value also has good convergence with the torque magnitude, obtained during field calculations (Fig. 3).

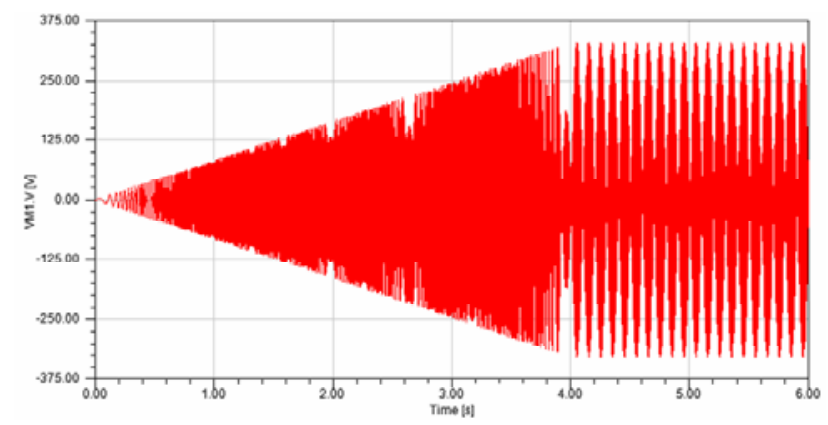

Fig. 13. Motor one phase voltage vs time

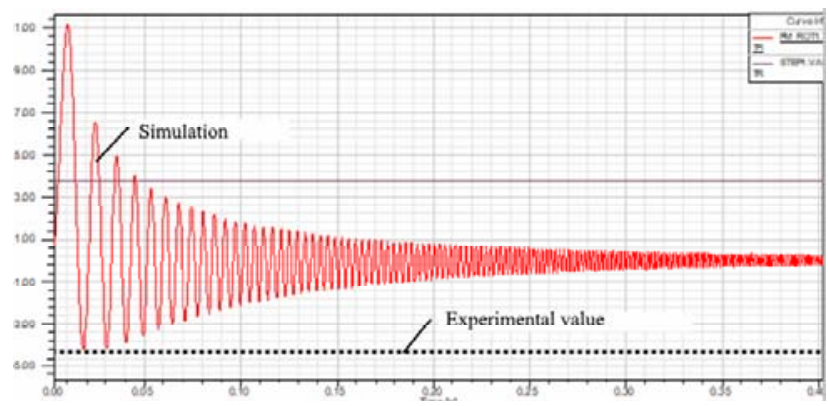

Fig. 14. Motor torque chart (full time range) with brake values

The characteristics of the motor torque for the mode without vibration on Fig. 15 is shown (scaled section on the time axis). The dashed line indicates the torque magnitude registered in experiment. This value also has good convergence with the torque magnitude, obtained in field calculations (Fig. 4).

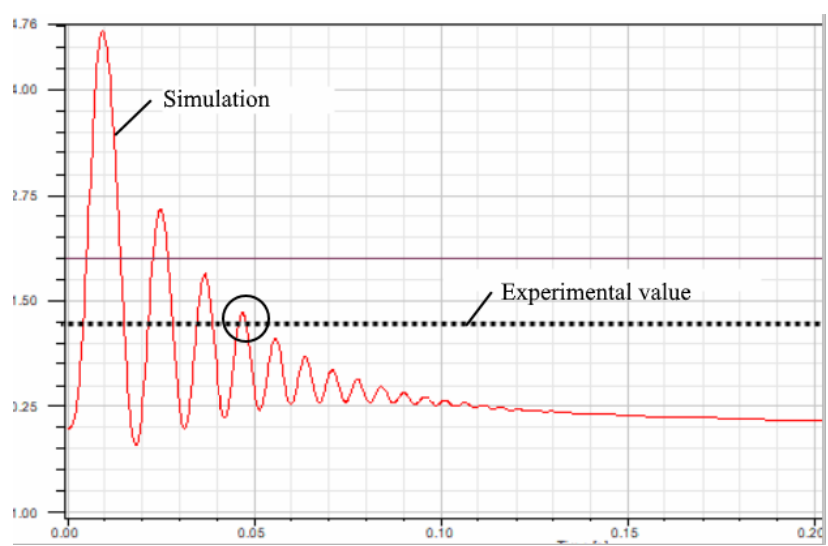

Fig. 15. Motor torque chart (scaled time range) without brake values

Comparative characteristics of the modeling results and experimental studies in Table 3 is given.

As follows from the given research results, the dependences of speed and voltage correspond to the task of equations (2) - (3) and accurately represent the set values of the control system.

Table 3

Results of imitation modeling and experiment

\begin{tabular}{|l|c|c|c|}
\hline \multicolumn{1}{|c|}{ Parameter Name } & Model & Experiment & Deviation,\% \\
\hline Rated current, A & 39.1 & 39.05 & 0.13 \\
\hline Rated speed, rev/min & 30064 & 29994 & 0.23 \\
\hline $\begin{array}{l}\text { Negative starting torque } \\
\text { value, Nm }\end{array}$ & -4.8 & -4.5 & 6.67 \\
\hline $\begin{array}{l}\text { Positive starting torque value, } \\
\text { Nm }\end{array}$ & 1.3 & 1.2 & 8.33 \\
\hline
\end{tabular}

The results of the simulation were compared with actual factory experiments and have a good correlation (minimum deviation $0.13 \%$, maximum $8.33 \%$, average error $3.84 \%$ ) with experimental data from a certified factory laboratory.

\section{Conclusions.}

1. The simulation model of a high-speed induction motor with scalar frequency control in Ansys \& Simplorer has been developed and investigated using parallel modeling on a cluster of high-performance computations, which makes it possible to create simulation models that are close to their physical prototypes. The results of the 
simulation have good convergence with the results of experimental studies (deviation is not more than $8.33 \%$ ).

2. Using the simulation model, the correlation between the number of stator and rotor slots and the number of pole pairs of a high-speed induction motor with a rated frequency above $200 \mathrm{~Hz}$ is obtained for the first time and can significantly reduce vibration and noise in the motor start-up mode.

3. The developed simulation model of a high-speed induction motor allows to optimize its characteristics without using expensive actual tests and can be widely used both in the development of induction motors and in the educational process.

\section{REFERENCES}

1. Ansys Maxwell $2 D \quad$ v.15 - Electromagnetic and Electromechanical Analysis: users guide. Ansys, Inc., Pittsburgh, release 15.0, 2012. $628 \mathrm{p}$.

2. Ansys Maxwell $3 D$ v.15 - Electromagnetic and Electromechanical Analysis: users guide. Ansys, Inc., Pittsburgh, release 15.0, 2012. $1006 \mathrm{p}$.

3. Electric machines considering power electronics. Ansys, Inc., Pittsburgh, 2012, 58 p.

4. The design of electric machines using Maxwell and Simplorer. Ansys, Inc., 2013. 48 p.

5. Zhao X., Liu H., Zhang J., Zhang H. Simulation of field oriented control in induction motor drive system. TELKOMNIKA Indonesian Journal of Electrical Engineering, 2013, vol.11, no.12, pp. 7555-7563. doi: 10.11591/telkomnika.v11i12.3674.

6. Behera P.K., Behera M.K., Sahoo A.K. Speed control of induction motor using scalar control technique. International Journal of Computer Applications, 2014, no.1, pp. 37-39.

7. Apostoaia C.M. Co-simulation platform for AC drives control systems. Proc. WASET International Conference on Electric Machines and Drive Systems (ICEMDS '2012), Paris, France, Nov. 2012, pp. 1879-1886.

8. Ramesh K., Kumar C.R., Murali P.B. Modeling and implementation of vector control for induction motor drive. International Journal of Computer Applications, 2015, vol.3, no.2, pp. 80-91.
9. 32-BIT Microcontroller 3-Phase ACIM Scalar Control Application Note. Spansion, Inc., revision 1.0, 2015. 22 p.

10. Scalar (V/f) Control of 3-Phase Induction Motors. Texas Instruments, Inc., sPRABQ8, 2013. 25 p.

11. Zelenov A.B. Teorijaj elektroprivoda [Electric drive theory]. Alchevsk, 2005. 508 p. (Rus).

12. Zablodskii N.N., Pliugin V.E., Petrenko A.N. Using of object-oriented design principles in electric machines development. Electrical Engineering \& Electromechanics, 2016, no.1, pp. 17-20. doi: 10.20998/2074-272X.2016.1.03.

13. Zablodskij N., Pliugin V., Fligl S., Lettl J. Dynamic simulation of the double-stator induction electromechanical converter with ferromagnetic rotor. 4th International Conference on Power Engineering, Energy and Electrical Drives, Istanbul, Turkey, May 2013, pp. 1448-1453. doi: 10.1109/powereng.2013.6635828.

14. Zablodskii N.N., Plyugin V.E., Gritsyuk V.Y., Grin' G.M. Polyfunctional electromechanical energy transformers for technological purposes. Russian Electrical Engineering, 2016, vol.87, no.3, pp. 140-144. doi: 10.3103/s1068371216030123.

15. Zablodskiy N., Pliugin V. 3D magnetic filed distribution in a screw double-stator induction motor. 2015 16th International Conference on Computational Problems of Electrical Engineering (CPEE), Lviv, Ukraine, Sep. 2015, pp. 239-241. doi: 10.1109/cpee.2015.7333386.

Received 01.10.2017

V. Pliugin ${ }^{1}$, Doctor of Technical Sciences, Professor,

O. Petrenko ${ }^{1}$, Candidate of Technical Sciences, Associate

Professor,

V. Grinina ${ }^{1}$ PhD Student,

O. Grinin ${ }^{1}$, Engineer,

A. Yehorov ${ }^{2}$, Candidate of Technical Sciences, Associate

Professor,

${ }^{1}$ O.M. Beketov National University of Urban Economy in Kharkiv,

17, Marshal Bazhanov Str., Kharkiv, 61002, Ukraine, e-mail: vlad.plyugin@gmail.com

${ }^{2}$ National Technical University «Kharkiv Polytechnic Institute»,

2, Kyrpychova Str., Kharkiv, 61002, Ukraine.

How to cite this article:

Pliugin V., Petrenko O., Grinina V., Grinin O., Yehorov A. Imitation model of a high-speed induction motor with frequency control. Electrical engineering \& electromechanics, 2017, no.6, pp. 14-20. doi: 10.20998/2074272X.2017.6.02. 